\title{
EXPERIMENTAL INVESTIGATIONS IN DRAFT RESISTANCE OF SPHERICAL WORKING TOOL OF DISK HARROW
}

\author{
Volodymyr Bulgakov ${ }^{1}$, Simone Pascuzzi ${ }^{2}$, Semjons Ivanovs ${ }^{3}$, Volodymyr Volskyi ${ }^{4}$ \\ ${ }^{1}$ National University of Life and Environmental Sciences of Ukraine, Ukraine; \\ ${ }^{2}$ University of Bari Aldo Moro, Italy; ${ }^{3}$ Latvia University of Life Sciences and Technologies, Latvia; \\ ${ }^{4}$ National Scientific Centre "Institute for Agricultural Engineering \\ and Electrification" of Ukraine, Ukraine \\ semjons@apollo.lv
}

\begin{abstract}
Spherical working tools find wide application in soil tillage, particularly in various designs of harrows. Despite the many advantages and many years' practical use, there is a need for a detailed assessment of the power characteristics of spherical disks when interacting with different types of soil in order to improve labour efficiency and reduce the specific energy costs. Experimental investigations were carried out under the field conditions using an experimental installation and specimens of tillage tools. In order to study the draft resistance of the working tool, the tensometry method was used. The obtained data were processed by the methods of mathematical statistics, as well as the dispersion and regression analysis using a PC and the corresponding software. According to the results of the research a special methodology was proposed for the determination of the power characteristics of a spherical disk working tool depending on the conditions of its operation, provided that the technological process is ensured. Using the results of the experimental studies, regression equations were obtained and the dependences of energy consumption upon the operating conditions of the spherical disk working tool were constructed. The tractive force of the spherical disk varies within the range from $88.2 \mathrm{~N}$ (at the depth of $6 \mathrm{~cm}$ ) to $1985.0 \mathrm{~N}$ (at the depth of $h=18 \mathrm{~cm}$ ).
\end{abstract}

Keywords: disk, harrow, draft resistance, tillage, installation, sensor.

\section{Introduction}

Despite the emergence of new trends, mechanical tillage is still the most important operation in the technology of field crop cultivation [1]. Due to the high energy consumption in mechanical tillage the task to minimise energy consumption is urgent and requires further scientific research [2].The soil tillage implements with spherical disk working tools are widely used in all kinds of tillage, ranging from shallow stubble skimming after the harvest to the basic tillage of the soil [3]. These implements of a relatively simple design have a series of advantages [4]; in particular, many authors point to the relatively lower energy consumption for the implementation of a similar technological process of tillage. The work of disc tillage machines was investigated by many scientists in Europe and the world [2-4]. However, the available research results do not allow an objective assessment of the power characteristics of a spherical disk working tool when it interacts with the soil, in order to increase its efficiency and reduce the specific energy cost. Therefore, there is a need to develop a special methodology for experimental determination of the components of the resistance force of a spherical disk working tool.

The purpose of the research is to determine the power indicators of the components of the resistance force of a spherical disk working tool depending on the conditions of its operation, provided that the technological process is ensured.

\section{Materials and methods}

To study the draft resistance of the working tool the tensometric method was used. The obtained data were processed by the methods of mathematical statistics, as well as the dispersion and regression analysis using a PC and the corresponding software. The program of the experimental investigations included:

- determination of conditions for conducting the experimental investigations (hardness, humidity, density);

- determination of indicators of the resistance forces (longitudinal $P_{x}$, transverse $P_{y}$, vertical $P_{z}$ ) of the disk working tool depending on the disking depth $h$ of the soil and the forward speed $V_{n}$;

- determination of how well execution of the technological process of soil tillage by the spherical disk working tool is ensured. 
The type of the soil and designation by its mechanical composition were selected from the soil map of the area. The research of the processing quality indicators was determined in accordance with the standard [5]. The moisture of the soil was determined by triple taking soil samples in sample cups (bottles), weighing them and then drying to a dry state in the drying box; the absolute and relative soil moisture were determined. The soil hardness was determined by a penetrometer according to the known methodology [6]. A comparative assessment of the tillage quality by the spherical disk working tool was executed by determining the structural and aggregative state of the soil after the passage of the disk, using a standard methodology [5]. To carry out the experimental investigations, a soil tillage aggregate was used consisting of a source of power (a YuMZ-6KL tractor) and a mounted experimental installation for measuring the component resistance forces of the spherical disk working tool (Fig. 1).

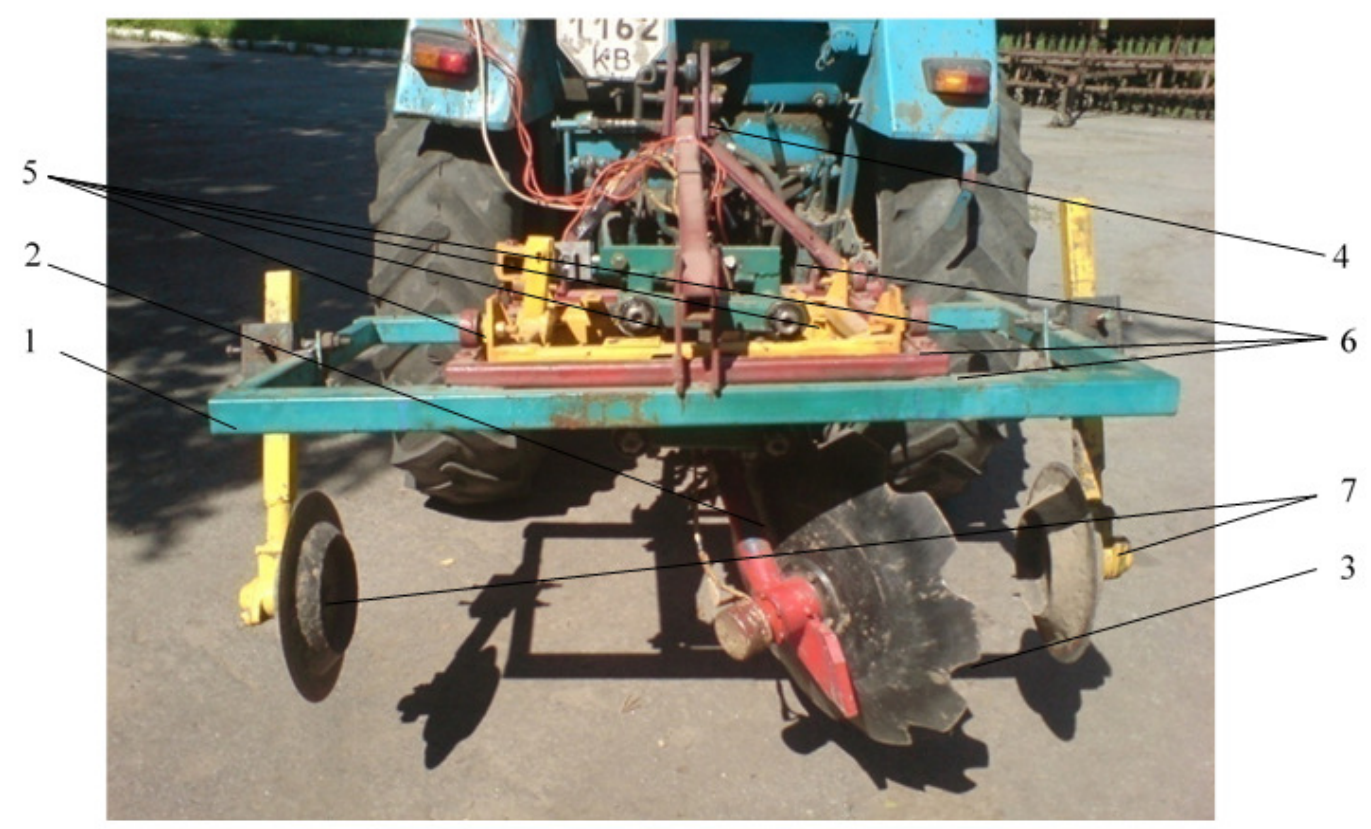

Fig. 1. General view of experimental installation (the rear view): 1 - frame; 2 - disc rack;

3 - spherical disk; 4 - hitch element; 5 - bearing units; 6 - frames; 7 - stabilisation disks

The principle of operation of the spherical disk working tool with a solid (i.e. circumferentially) working blade and a cutout is the same. However, in terms of the energy consumption and performance indicators, the disks with a cutout blade have an advantage [4;7]; therefore, in the experimental installation, a spherical disk tool with cutouts of the blade was used, the technical characteristics of which are shown in Table 1. The quality of the weed trimming within the furrow width, obtained in one run of the spherical disk working tool, was determined according to the methodology [5].

Table 1

Technical characteristics of a spherical disk working tool of a disk harrow

\begin{tabular}{|l|c|c|}
\hline \multicolumn{1}{|c|}{ Name of the parameter } & Unit of measurement & Value of the parameter \\
\hline Operating width & $\mathrm{m}$ & 0.3 \\
\hline Tillage depth & $\mathrm{m}$ & $0.06 ; 0.12 ; 0.18$ \\
\hline Shape of the working tool & - & A cutout spherical disk \\
\hline Number of cutouts & piece & 10 \\
\hline Diameter of the disk & $\mathrm{m}$ & 0.66 \\
\hline Radius of the sphere of the disk & $\mathrm{m}$ & 0.66 \\
\hline Disk approach angle & $\mathrm{deg}$. & 30 \\
\hline Disk inclination angle & $\mathrm{deg}$. & 15 \\
\hline Operating speed & $\mathrm{km} \cdot \mathrm{h}^{-1}$ & up to 7.6; $9.0 ; 11.1$ \\
\hline
\end{tabular}


The experimental installation was equipped with three tensometric sensors DEF-A2t, the data from which were recorded and processed (digital array) by means of a computer with the software ADA-1406 using the analog-digital converter (ADC) ADA-1406 (Fig. 2).

Calibration of the sensors was carried out under laboratory conditions using the same recording equipment, which is placed directly on the experimental installation. Since a spherical disk working tool with ten cutouts on the blade was selected for the experimental investigations, it can be assumed that the strain will vary 10 times with each rotation of the disk. Considering this, the required number of measurements corresponded to the reliability of obtaining experiments $H=0.99$ and the relative error $\Delta=0.2$ [6]. That is, when $\Delta= \pm 3 \sigma$, the most possible statistical error will be equal to $\pm 3 \sigma / a \cdot 100 \%$ ( $a$ is the average measuring resistance force). To achieve this, it is necessary to make 100 measurements, that is, when the disk is moving at a speed of $V_{n}=2 \mathrm{~m} \cdot \mathrm{s}^{-1}$, measurements were taken for 10 rotations of the disk, which is equal to the speed of the movement of the disk $V_{n}=7.2 \mathrm{~km} \cdot \mathrm{h}^{-1}$; the measurements were made for a section, $20 \mathrm{~m}$ long; the data recording continued for $10 \mathrm{~s}$. If the speed of the movement increases, the recording time can be proportionally reduced and, vice versa, - when the speed of the disk decreases, the data recording time should proportionally increase.

For experimental investigations there was selected a spherical disk with cutouts of the blade with the diameter of $D_{d}=660 \mathrm{~mm}$, the sphere radius of $R_{s}=660 \mathrm{~mm}$, the disk approach angle $\alpha=30^{\circ}$, the inclination angle of the disk plane to the vertical $\beta=15^{\circ}$. The speed of the forward movement corresponded to the calculated speeds without slipping at the rated nominal power of the YuMZ-6KL tractor, which amounted to $7.6 \mathrm{~km} \cdot \mathrm{h}^{-1}$ on the first gear, the $2 \mathrm{nd}$ one $-9.0 \mathrm{~km} \cdot \mathrm{h}^{-1}$, the $3 \mathrm{rd}-$ $11.1 \mathrm{~km} \cdot \mathrm{h}^{-1}$. The exact value of the speed of the experimental installation during the experiments was determined using a track measuring wheel. The depth of the soil tillage with the spherical disk was set exactly, and it was 6,12 and $18 \mathrm{~cm}$. Determination of the indicators of the component resistance force of the disk working tool was carried out by the tensometric method [8-12]. The following forces were fixed: the longitudinal $P_{x}$, transverse $P_{y}$, and the vertical $P_{z}$ resistance forces depending on the tillage depth $h$ and the speed $V$ of the aggregate. These investigations were conducted in a specially selected area of the field with a size of $50 \times 50 \mathrm{~m}$. All the experimental studies were performed in triplicate. Processing of the results took place by the methods of mathematical statistics, as well as the dispersion and regression analysis using a PC and the corresponding software.

The agrotechnical assessment of the soil tillage by the disk tillage tool, carried out in accordance with the item indication (nomenclature) indicators of the test conditions, and the quality of the technological process are shown in Table 2. Triple repetition of measurements. The technological process of tillage by means of spherical disk working tools is characterised by a number of structural and operating parameters that affect the quality and energy indicators of the process. The methodology envisaged for obtaining dependent factors in the form of regression equations. To find the regression coefficients, a series of experiments were carried out according to a previously adopted plan, which showed the number and conditions of the experiments.

Indicators of the test conditions and quality of technological operations

Table 2 for agrotechnical assessment

\begin{tabular}{|c|c|}
\hline Indicators of the test conditions & $\begin{array}{c}\text { Indicators of the technological } \\
\text { process }\end{array}$ \\
\hline $\begin{array}{c}\text { Soil type and designation by its } \\
\text { mechanical composition }\end{array}$ & Speed of the movement, $\mathrm{km} \cdot \mathrm{h}^{-1}$ \\
\hline Soil background & Working width, $\mathrm{m}$ \\
\hline Soil moisture, $\%$ & Depth of tillage, $\mathrm{cm}$ \\
\hline Soil density, $\mathrm{g} \cdot \mathrm{cm}^{-3}$ & Soil crumpling degree, $\%$ \\
\hline
\end{tabular}

The choice of independent factors to obtain the equations of regression was made according to preliminary theoretical studies that showed the effect of individual factors in a certain range of values upon the energy indicators of tillage [12-14]. Independent factors that were used in the study: $x_{1}=h-$ the depth of tillage, $\mathrm{cm} ; x_{2}=V-$ the speed of the forward movement of the aggregate, $\mathrm{km} \cdot \mathrm{h}^{-1}$. The planning matrix of experiments was fulfilled according to the plan of a full-factor experiment of the 
second order [5, 13-15].It was supposed to use three levels for each independent factor: the upper $(+1)$, the medium $(0)$ and the lower $(-1)$ factor. The value of levels and intervals of variation for independent factors are given in Table. 3

Table 3

Value and coding of the levels of the factors

\begin{tabular}{|c|c|c|}
\hline \multirow{2}{*}{ Level of variation } & \multicolumn{2}{|c|}{ Independent factors } \\
\cline { 2 - 3 } & $x_{1}$ & $x_{2}$ \\
\hline Lower $(-1)$ & 6 & 7.6 \\
\hline Medium (0) & 12 & 9.0 \\
\hline Upper (+1) & 18 & 11.1 \\
\hline
\end{tabular}

According to the assessment of the obtained indicators of the disk operation, the following dependent factors are taken: $P_{x}, P_{y}, P_{z}-$ the longitudinal, lateral and vertical components of the resistance force $\mathrm{N}$, respectively. The mathematical empirical model of the impact of independent factors upon the evaluation criteria (the regression equation) was represented as a polynomial of the second degree, and it looked like:

$$
Y=b_{0}+\sum_{i=1}^{k} b_{i} \cdot x_{i}+\sum_{i=1}^{k} b_{i i} \cdot x_{i}^{2}+\sum_{i<j}^{k} b_{i j} \cdot x_{i} \cdot x_{j}+\ldots,
$$

where $b_{i}, b_{i i,}, b_{i j}-$ regression coefficients of the $i$-th factor, the paired and the quadratic interactions, respectively;

$k$ - number of factors.

The regression coefficients, analysis of equations, significance, adequacy, reproducibility and homogeneity, the construction of response surfaces and other graphical interpretation of the results, their optimisation were determined by standard methods using the MathCad 13, MatLab 6.0, Statistica 6.0 and STAT.EXE programs. The mathematical processing of the obtained data, as well as the calculation of the statistical characteristics were performed by means of the above-mentioned programs.

The laboratory and field investigations of the spherical disk working tool were conducted on the experimental plots of the NSC "IMESG" (Glevakha, Kiev Region, Ukraine) in the forest-steppe zone of black soil (chernozem) area with medium loamy soil (Fig. 3).

For experimental investigations a research site of a field, measuring $50 \times 50 \mathrm{~m}$, was selected, on which experimental plots, measuring $30 \times 2.5 \mathrm{~m}$, were separated. The research conditions are given in Table. 4. To measure forces $P_{x}, P_{y}, P_{z}$ of the draft resistance of the spherical disk working tool, an experimental installation (Fig. 3) was used, equipped with two stabilisation disks to stabilize the movement of the spherical disk working tool in the longitudinal direction, in which the value of the strain was measured.

Table 4

\section{Research conditions}

\begin{tabular}{|l|c|c|c|}
\hline \multicolumn{1}{|c|}{ Name of the indicator } & Designation & Unit of measurement & Value \\
\hline Type of the soil & \multicolumn{3}{|c|}{ black soil (chernozem) area with medium loamy soil } \\
\hline Relief & \multicolumn{3}{|c|}{ flat } \\
\hline Microrelief & \multicolumn{3}{|c|}{ levelled } \\
\hline Background & \multicolumn{3}{|c|}{ compacted chernozem } \\
\hline Average hardness of the soil & $\rho$ & $\mathrm{mPa}$ & 2.3 \\
\hline Soil density & & & $\mathrm{g} \cdot \mathrm{cm}^{-3}$ \\
\hline Soil moisture at the depth: & & & $1.10-1.25$ \\
$5 \mathrm{~cm}$, & $W$ & & 18.3 \\
$10 \mathrm{~cm}$, & & & 20.3 \\
$15 \mathrm{~cm}$, & & & 21.6 \\
$20 \mathrm{~cm}$ & & & 20.0 \\
Average moisture of the soil: & & & \\
\hline
\end{tabular}




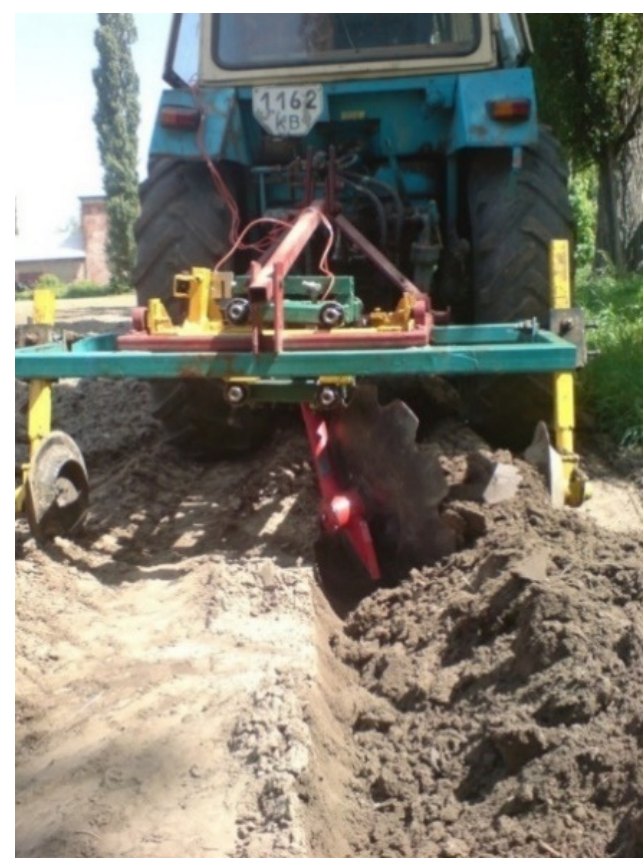

Fig. 3. View of furrow after passage of experimental installation

\section{Results and discussion}

Figure 4 shows a general view of the oscillogram of the recorded forces $P_{x}, P_{y}, P_{z}$ acting upon the spherical disk working tool.

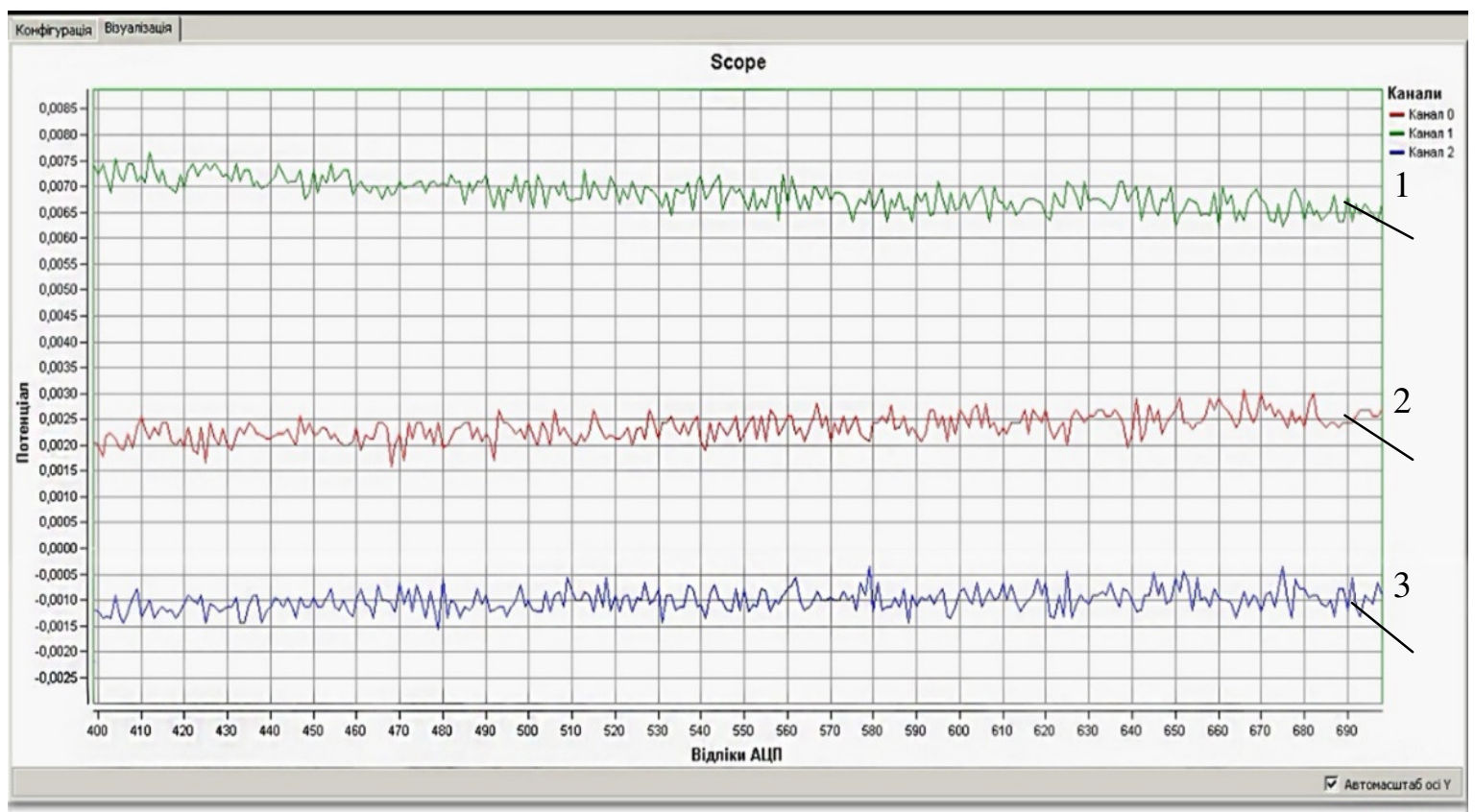

Fig. 4. Part of oscillogram of recorded forces acting upon working tool:

1 - longitudinal (channel-1); 2 - transverse (channel-0); 3 - vertical (channel-2)

Figs. 5, 6, and 7 show dependences of the longitudinal $P_{x}$, the lateral $P_{y}$, and the vertical $P_{z}$ forces, acting upon the spherical disk tool, when the speed of the movement $V_{n}$ and the disking depth of the soil $h$ are changed.

The regression equations obtained:

$$
P_{x}\left(V_{n}, h\right)=787.7-228.29 h-93.6 V_{n}^{2}+1.4 h^{2}+29.4 h V_{n}
$$


In Fig. 5 there is presented the dependence of the longitudinal force $P_{x}$ upon the speed of the movement of the disk $V_{n}$ and the depth of the soil tillage $h$.

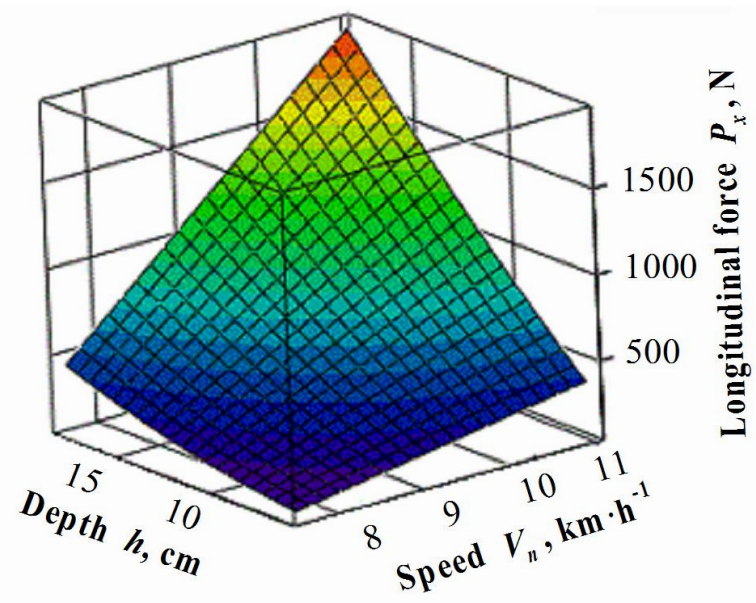

Fig. 5. Dependence of longitudinal force $\boldsymbol{P}_{x}$ upon change in speed of movement $V_{n}$ and depth of soil tillage $h$ $V_{n}$ and $h$.

Using the regression equation (3), in Fig. 6 there is reflected the dependence of the force $P_{y}$ upon

$$
P_{y}\left(V_{n,} h\right)=997.742-90.86 h-184.34 V_{n+0.755 h^{2}}+12.43 h V_{n}+7.7 V_{n}^{2} .
$$

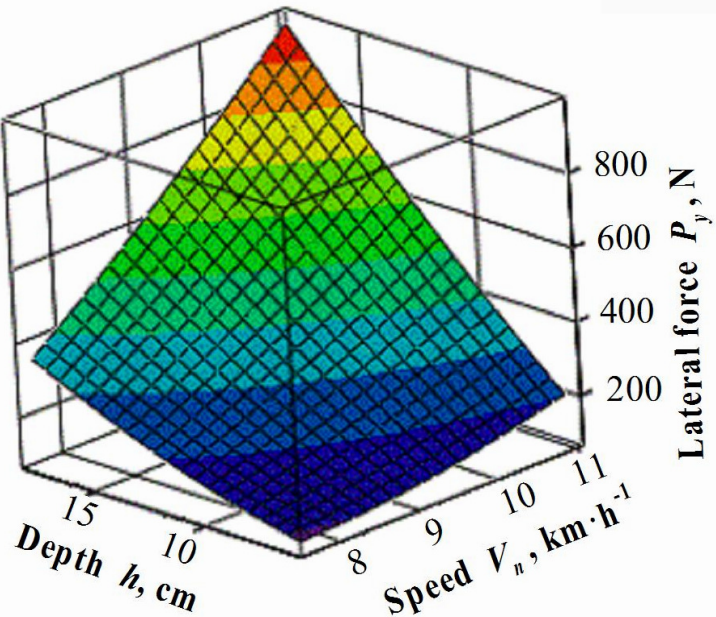

Fig. 6. Dependence of lateral force $\boldsymbol{P}_{\boldsymbol{y}}$ upon speed of movement $\boldsymbol{V}_{\boldsymbol{n}}$ and depth of soil tillage $\boldsymbol{h}$

According to the regression equation:

$$
P_{z}\left(V_{n}, h\right)=24.83+15.49 h+0.24 h^{2}+2.48 h V_{n}-0.43 V_{n}^{2} .
$$

In Fig. 7 there is shown the dependence of the vertical force $P_{z}$ upon the speed of the movement $V_{n}$ and the depth of the soil tillage $h$.

According to the regression equation:

$$
P\left(V_{n} h\right)=842.45-242.19 h-100.86 V_{n}^{2}+1.63 h^{2}+31.7 h V_{n} .
$$

In Fig. 8 there is presented a graph of the variations in the generalised force $P$ acting on the spherical disk working tool depending upon the speed of the movement $V_{n}$ and the depth of the soil tillage $h$. 


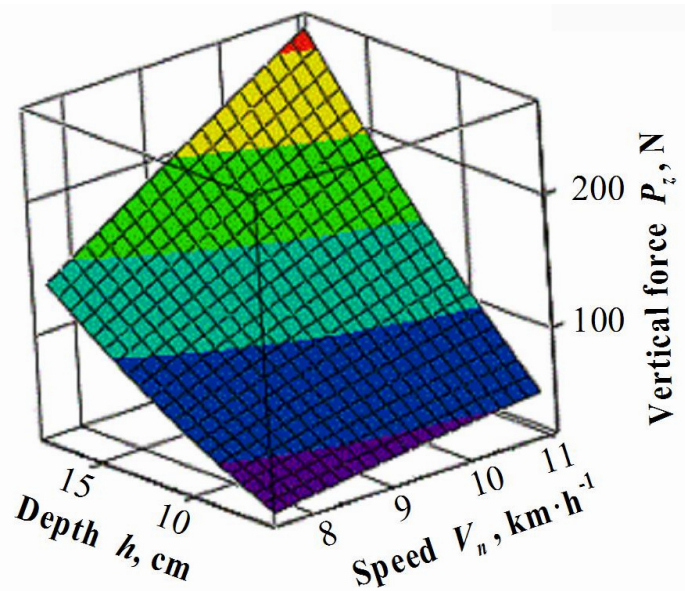

Fig. 7. Dependence of vertical force $P_{z}$ upon speed of movement $V_{n}$ and depth of soil tillage $h$

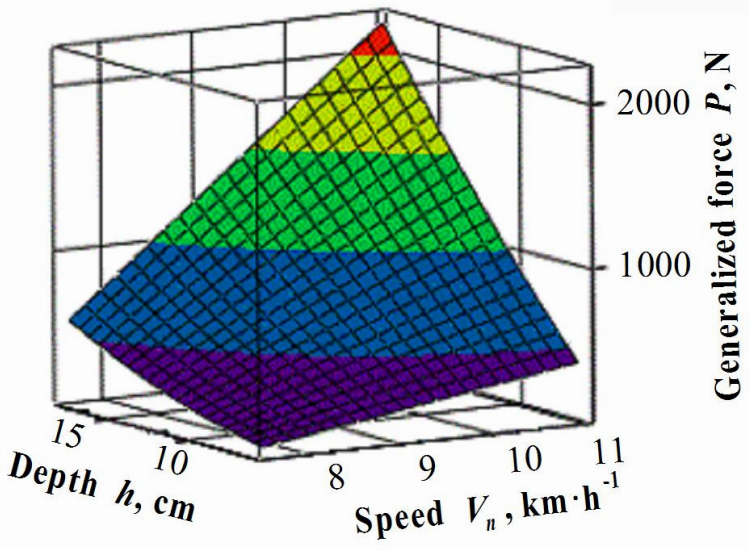

Fig. 8 Dependence of generalised force $P$ upon speed of movement $V_{n}$ and depth of soil tillage $h$

Having considering the above formulas of regression (2-5), we can draw a conclusion about their quadratic nature:

$$
P_{x}=f\left(V_{n} h\right) P_{y}=f\left(V_{n} h\right) P_{z}=f\left(V_{n} h\right)
$$

It should be noted that the function $P=f\left(V_{n} h\right)$ Error! Bookmark not defined. has no practical value for the operation. In the operational aspect it is more expedient to perform an analysis of $P_{x}$, which is the value of the tractive force, $P_{y}$ is important as a force that needs to be balanced when the spherical disk working tool of the harrow is operating, and $P_{z}$ is important for the running uniformity by depth.

On the basis of the obtained experimental data it is possible to analyse the nature of the change in the specific tractive force depending on the depth of disking at a speed of $V_{n}=11.1 \mathrm{~km} \cdot \mathrm{h}^{-1}$, for $D_{d i s}=660 \mathrm{~mm}, R_{s f}=660 \mathrm{~mm}, \alpha=30^{\circ}, \beta=15^{\circ}$. The specific tractive force, when disking, varies from $3.5 \mathrm{~N} \cdot \mathrm{cm}^{-2}$ at the depth of $h=6 \mathrm{~cm}$ to $3.24 \mathrm{~N} \cdot \mathrm{cm}^{-2}$ at the depth of $h=18 \mathrm{~cm}$. At the depth of disking $h=12 \mathrm{~cm}$, the specific tractive force is $3.05 \mathrm{~N} \cdot \mathrm{cm}^{-2}$.

Depending on the depth of disking, the data about the values of the specific tractive force are approximated by a mathematical expression:

$$
P_{n}=0.375 h^{2}-1.625 h+4.75
$$

The graph of variations in the specific tractive force as a function of the depth of disking is shown in Fig. 9, from which it can be concluded that the minimum specific tractive force is observed, when the disking depth of the soil is $h=12-16 \mathrm{~cm}$.

Table 5 presents the calculated data of the statistical error of the measurement of the tractive force $P_{x}$ of the spherical disk working tool. All the values of the tractive force $P_{x}$ within the range $P_{x \pm} \Delta_{n}$, are within the range of the measurement accuracy, and its value, obtained during the 
measurement, is within the range $0.49 \ldots 0.73$ at the disking depth $h=6 \ldots 18 \mathrm{~cm}$ and the speed $V_{n}=7.6 \ldots 11.1 \mathrm{~km} \cdot \mathrm{h}^{-1}$, which does not go beyond the limits $x-a \leq \Delta_{n}$ and does not fall within the random error zone.

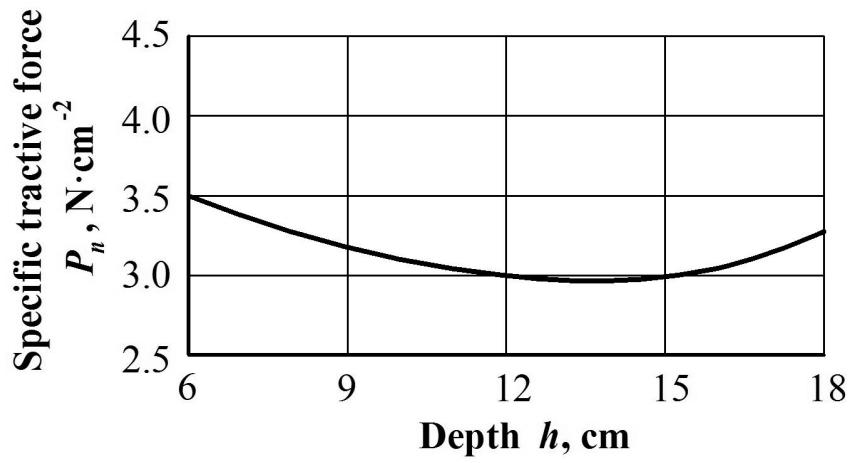

Fig. 9. Dependence of specific tractive force $\boldsymbol{P}_{\boldsymbol{n}}$ upon depth of disking $\boldsymbol{h}$

$$
\left(D_{\text {dis }}=660 \mathrm{~mm}, R_{s f}=660 \mathrm{~mm}, \alpha=30^{\circ}, \beta=15^{\circ}, V_{n}=11.1 \mathrm{~km} \cdot \mathrm{h}^{-1}\right)
$$

Due to the fact that the experimental investigations were carried out with a single working tool $-\mathrm{a}$ spherical disk, in the process of recording the results of the tensometric measurements of the tractive force there were simultaneously determined the lateral and the vertical forces acting upon this body, and the degree of the soil loosening, that is, the structure of the soil in one furrow made by the disc during the operating run.

Table 5

\section{Calculated data of the statistical error of the measurements of the tractive force $P_{x}$ of the spherical disk working tool}

\begin{tabular}{|c|c|c|c|c|c|c|}
\hline \multirow{2}{*}{$\begin{array}{c}\text { Soil tillage } \\
\text { depth, cm }\end{array}$} & \multicolumn{6}{|c|}{ Speed of the movement, $\mathbf{~ k m} \cdot \mathbf{h}^{-1}$} \\
\cline { 2 - 7 } & \multicolumn{2}{|c|}{7.6} & \multicolumn{2}{|c|}{9.0} & \multicolumn{2}{c|}{11.1} \\
\cline { 2 - 7 } & error & $\%$ & error & $\%$ & error & $\%$ \\
\hline 6 & 0.548 & 54.8 & 0.740 & 74.0 & 0.62 & 62 \\
\hline 12 & 0.519 & 51.9 & 0.696 & 69.6 & 0.73 & 73 \\
\hline 18 & 0.490 & 49.0 & 0.580 & 58.0 & 0.67 & 67 \\
\hline
\end{tabular}

In addition, all the soil, cut by the disk per meter of the furrow in three repetitions, was collected; it was screened, using a sieve, into fractions: $<1,1-5,5-10$ and $>10 \mathrm{~mm}$ (Table 6). Table 6 shows the results of determination of the aggregative state of the soil in accordance with the standard method [4] after the run of the spherical disk working tool.

\section{Results of determination of the aggregative state of the soil} after the run of the spherical disk working tool

\begin{tabular}{|c|c|c|c|c|c|}
\hline \multirow{2}{*}{ Repetitions } & \multicolumn{4}{|c|}{ Aggregative composition, $\%$} & \multirow{5}{*}{$\begin{array}{c}\text { Structural } \\
\text { coefficient of } \\
\text { the cultivated } \\
\text { soil }\end{array}$} \\
\hline & $<1 \mathrm{~mm}$ & $1-5 \mathrm{~mm}$ & $5-10 \mathrm{~mm}$ & $>10 \mathrm{~mm}$ & \\
\hline 1 & 15.60 & 34.80 & 19.70 & 30.10 & \\
\hline 2 & 13.80 & 36.20 & 18.60 & 31.40 & \\
\hline 3 & 14.20 & 35.70 & 20.30 & 29.80 & \\
\hline Average value & 14.53 & 35.56 & 19.53 & 30.43 & 0.69 \\
\hline
\end{tabular}

\section{Conclusions}

1. The tractive force of the spherical disk varies within the range from $88.2 \mathrm{~N}$ (at the depth of $h=6 \mathrm{~cm}, V_{n}=7.6 \mathrm{~km} \cdot \mathrm{h}^{-1}$ ) to $1985.0 \mathrm{~N}$ (at the depth of $h=18 \mathrm{~cm}$ and $V_{n}=11.1 \mathrm{~km} \cdot \mathrm{h}^{-1}$ ). The nature of this variation has been analysed.

2. The specific tractive force of disking $P_{n}$ was determined and analysed at the speed of the movement $V_{n}=11.1 \mathrm{~km} \cdot \mathrm{h}^{-1}$, when the soil tillage depth $h$ was changed from 6 to $18 \mathrm{~cm}$. It has 
been established that this minimum specific force is within the range of $3.05-3.50 \mathrm{~N} \cdot \mathrm{cm}^{-2}$ at the disking depth $h=12-16 \mathrm{~cm}$.

3. A possible statistical error $\Delta_{n}$ has been determined at the disking depth $h=6-18 \mathrm{~cm}$ and the speed of the movement $V_{n}=7.6-11.1 \mathrm{~km} \cdot \mathrm{h}^{-1}$, which is within the range $0.49-0.73$.

\section{References}

[1] Barwicki J., Gach St., Ivanovs S. Proper utilization of soil structure for crops today and conservation for future generations. Engineering for Rural Development, proceedings, Vol. 11, 2012, pp. 10-15;

[2] Rucins A., Vilde A. Modelling forces acting on the plough body. Simulation in Wider Europe 19th European Conference on. Modelling and Simulation, ECMS 2005,2005, pp. 425-430;

[3] Гуков Я.С. Обработка почвы. Технология и техника. Механико-технологическое обоснование энергосберегающих средств для механизации обработки почвы в условиях Украины (Soiltillage. A technology and machines. Mechanical and technological substantiation of the energy saving means for mechanised soil tillage under the conditions of Ukraine.), Киев, 2007, 276 p. (In Ukrainian);

[4] Стрельбицкий В.Ф. Дисковые почвообрабатывающие машины (Thedisktillagemachines). Москва, 1978. 135 p. (In Russian);

[5] ГОСТ 20915-11. Сельскохозяйственная техника. Методы определения условий испытаний. (Agriculturalmachinery. Methods for the determination of the test conditions). Москва, 2011. $34 \mathrm{p}$;

[6] ДСТУ 4744:2007. Национальный стандарт Украины. Качество почвы. Определение структурно-агрегатного состава ситовым методом модификации Н.И. Саввинова. (Тhe quality of the soil. Determination of the structural-aggregate composition by N. I. Savvinov's sieve method of modification). Киев: ГоспотребстандартУкраины, 2008. 7 р.;

[7] Bulgakov V., Ivanovs S., Adamchuk V., Ihnatiev Y. Investigation of the influence of the parameters of the experimental spiral potato heap separator on the quality of work. Agronomy Research, Vol. 15(1), 2017, p. 44-54;

[8] Xiong, P., Yang, Z., Sun, Z., Zhang, Q., Huang, Y., Zhang, Z. Simulation analysis and experiment for three-axis working resistances of rotary blade based on discrete element method.Nongye Gongcheng Xuebao/Transactions of the Chinese Society of Agricultural Engineering, Vol. 34, Issue 18, 2018, pp. 113-121;

[9] Маленко В.И. Методы экспериментального определения силовых характеристик рабочих органов почвообрабатывающих

орудий (Methodsofexperimentaldeterminationofthepowercharacteristicsoftheoperatingtoolsofthesoiltillag eimplements), Новосибирск, 1992. 106 p. (In Russian);

[10] Bulgakov V., Zaryshnyak A., Beloev H., Ivanovs S. Investigation of amplitude-frequency characteristics of disturbing and control impacts of asymmetric swath header machine-and-tractor aggregate. Engineering for rural development, proceedings, Vol. 17, 2018, pp. 221-226;

[11]Высоцкий А.А. Динамометрирование сельскохозяйственных машин (Dynamometry of agricultural machines). Москва: Машиностроение, 1998. 290 p. (In Russian);

[12] Smith D.W., Sims B.G., O'Neill D.H. Testing and evalution of agricultural machinery and equioment. FAO Agricultural services bulletin, No 110, 1994, 288 p.;

[13] Nurmiev A., Khafizov C., Khafizov R.,Ziganshin B. Optimization of main parameters of tractor working with soil-processing implement. Engineering for Rural Development, proceedings, Vol.17, 2018, pp. 161-167;

[14]Доспехов Б.Методика полевого опыта (Methodology of a field experiment). Москва, 2012, 352 p. (In Russian);

[15] Spall J. C. Factorial Design for Efficient Experimentation: «Generating Informative Data for System Identification». IEEE Control Systems Magazine, 30 (5), 2010, pp. 38-53. 